\title{
Maintenance practices in Swedish industries: Survey results
}

\author{
Imad Alsyouf* \\ Department of Mechanical Engineering, School of Technology and Design, Växjö University, SE-35195 Växjö, Sweden
}

\section{A R T I C L E I N F O}

Article history:

Received 21 August 2007

Accepted 13 May 2009

Available online 27 May 2009

Keywords:

Maintenance practices

Survey

Sweden

Maintenance approaches

Proactive maintenance

\begin{abstract}
A B S T R A C T
The purpose of this paper is to investigate the maintenance practices that are used in Swedish industry. The study was performed by conducting a cross-sectional survey within Swedish firms that have at least 100 employees. The main results achieved from the study show that the role of maintenance is not highly recognised. There is a need to spend and invest more in maintenance, which is considered by the majority of Swedish industries as a necessary expense. Although about 13\% of the maintenance department time is spent on planning maintenance tasks, nevertheless, about one third of the time is spent on unplanned tasks. There is a need for more adoption of maintenance concepts such as total productive maintenance (TPM) and reliability-centred maintenance (RCM). The lack or ineffectiveness of planning and scheduling can significantly restrict the maintenance department in achieving its objectives and can thus prevent the company from maximising business profits and offering competitive advantages.
\end{abstract}

(c) 2009 Elsevier B.V. All rights reserved.

\section{Introduction}

Manufacturing firms are realising that there is a critical need for proper maintenance of production facilities and systems (Luxhoj et al., 1997; Stephen, 2000; Cholasuke et al., 2004; Meulen et al., 2008). Industrial plants, machinery and equipment are becoming technologically more advanced, and at the same time more complex and difficult to control. Just in time (JIT) management systems, lean and agile manufacturing, and the use of automated and integrated systems have made production systems increasingly vulnerable to risks and susceptible to diverse consequential effects due to breakdowns (Luce, 1999; Vineyard et al., 2000; Holmberg, 2001). Maintenance is a business function that serves and supports the primary process in an organisation. It is defined as the combination of all technical and associated administrative actions intended to retain an item in, or restore it to, a state in which it can perform its required function (British standard glossary of terms used in terotechnology, 1993). The maintenance process adds to customer value in terms

\footnotetext{
* Tel.: +46 47070 8494; fax: +46470 768540 .

E-mail address: Imad.Alsyouf@vxu.se
}

of profit, quality, time and service (Zhu et al., 2002). Therefore, the maintenance function has become essential for a manufacturing organisation to maintain its competitiveness (Al-Najjar and Alsyouf, 2004). Without wellmaintained equipment, a plant will be at a disadvantage in a market that requires low-cost products of high quality to be delivered quickly (Stephen, 2000; Swanson, 2001, 2003; Cholasuke et al., 2004). Kamoun (2005) emphasised that as enterprises and customers count on the availability, reliability and quality of service of corporate assets, any compromise in these areas will lead to both decreased revenues and increased costs. Bob (2007) reported that wasted energy from faulty or poorly maintained compressed air systems cost US industry up to $\$ 3.2$ billion annually. Alsyouf (2006) showed in a case study that there is the potential, in an ideal scenario, to improve a company's return on investment (ROI) by about $9 \%$. This figure represents a projected US\$ 8.4 million loss in profits that is caused by planned inoperative time and overall equipment effectiveness (OEE) elements. At least $14 \%$ of the potential improvements in ROI are directly related to the contribution of maintenance functions to lost profit, which is due to unplanned stoppages and bad quality caused by maintenance-related problems. However, maintenance tasks are becoming increasingly more 
complex. A typical manufacturing system consists not only of mechanical components, but also of other elements such as electronic, hydraulic, and electromechanical systems, software and human beings. This means that disturbances and deviations in the production process may occur due to different factors such as the failure of significant components of equipment, the quality of purchased material and spare parts, design, manufacturing process control, management systems and human error (Holmberg, 2001).

Various literature databases, including ScienceDirect (Elsevier), EMERALD and JSTOR, were reviewed for related literature using combinations of keywords such as maintenance practices, Sweden, Swedish industry and survey. The results of the search show that no previous works have dealt with maintenance practices in Swedish industries. However, two papers were based on conducting a survey within Swedish industries with a focus on maintenance management and advanced manufacturing systems, see Jonsson (1997, 2000). Thus, the purpose of this paper is to investigate empirically within Swedish industries which maintenance practices are deployed, and identify the factors that are the key ingredients of proper maintenance practices.

\section{Maintenance practices}

Proper maintenance practices can contribute to overall business performance through their impact on the quality, efficiency and effectiveness of a company's operations. This can enhance the company's competitiveness, i.e. productivity advantages, value advantages and long-term profitability (Alsyouf, 2004). Consequently, the shareholders, customers, and society can be affected positively, as illustrated schematically in Fig. 1.

In the following, we discuss and present key ingredients of maintenance practices. These practices are structured and presented according to an adapted, balanced scorecard framework that was suggested in Alsyouf (2006). Firstly, we discuss maintenance practices with respect to the innovation and growth perspective and also the maintenance perspective.

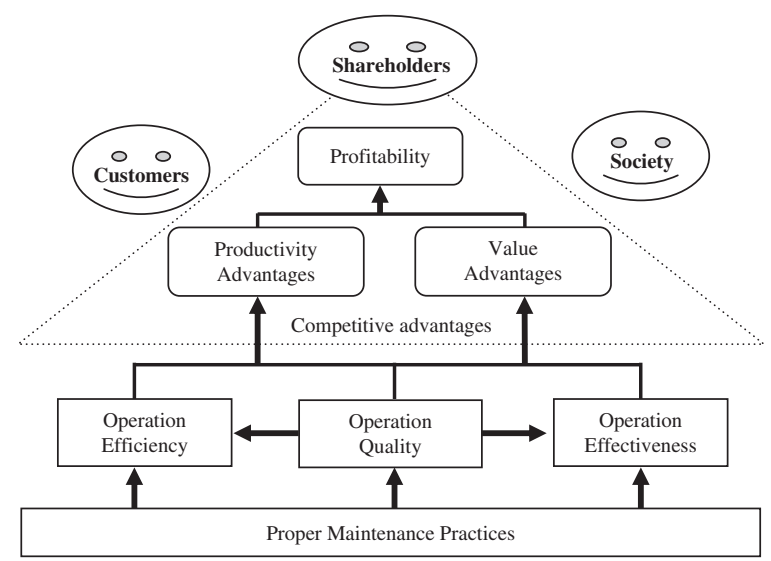

Fig. 1. Impact of proper maintenance practices on companies' competitive advantages.

\subsection{Innovation and growth perspective}

From the innovation and growth perspective, we focus on three related maintenance practices:

\subsubsection{Contributing to developing future machines}

The reliability and maintainability of production systems must be inherent within the early system design and development process (Kumar et al., 2007). Blanchard (2004) demonstrated that a large percentage (e.g. 70\% for some systems) of the total life cycle cost for a given system is attributed to operating and maintenance activities. A significant portion of this cost stems from the consequences of decisions made during the early phases of planning and conceptual design of the system. However, the reliability and maintainability of systems can be improved, depending on how advantages related to experience from older designs are taken into account. It is also very important that the designers are promptly informed about faults related to new equipment in use, since this enables them to take suitable measures to increase reliability. Thus, the contribution of maintenance departments in designing and improving production processes, and helping the purchasing department in selecting the right manufacturing equipment is considered an essential element of maintenance practice. Jonsson (1997) emphasised that feedback control loop of maintenance data is necessary to reduce the life cycle costs at an early stage, and implementation of a Deming plan-do-check-act-cycle (PDCA) is important to allow continuous improvement.

\subsubsection{Competence of maintenance workforce}

The competence of human resources in the maintenance department is considered an important factor in a successful maintenance program (Nakajima, 1988; Cholasuke et al., 2004; Kelly, 2006). Competence can be described as a combination of knowledge, skills, ability, willingness, interest and personal characteristics. Educational resources, which can include technical consultation as well as training, must be available and accessible to employees with identified needs (Tsang, 2002). Training should not be limited to the transfer of technical skills and knowledge needed for optimal task performance. It should also cover generic matters such as the business imperatives peculiar to the organisation, problem-solving techniques, and team dynamics (Tsang, 2002). Measures such as the qualifications of the maintenance labour force and the level of training and human resources development are considered to be among the critical characteristics of maintenance resources (Alsyouf, 2006). Dowlatshahi (2008) showed, in a survey conducted on Mexican (i.e. Maquiladore) industry, that the role of manufacturing operators was essential in the maintenance of machinery. The engineering departments did not adequately and forcefully participate in the design and troubleshooting activities of the tasks related to the maintenance department. 


\subsubsection{Investment in maintenance}

Investment in maintenance is considered a very important factor for leveraging the value of industrial assets. It could be in people, training or technology. In spite of the increasing awareness of maintenance and its influence on both enterprises and society, maintenance is still considered just as an unpredictable and unavoidable expense, i.e. a necessary evil. This could be due to, among other reasons, the difficulty of seeing the impact of maintenance on companies' bottom-line results (Bob, 2007; Alsyouf, 2007). Pinjala et al. (2006) showed, in an empirical study conducted in a sample of industry in Belgium and the Netherlands, that quality competitors with more advanced manufacturing technology usage and automation have more maintenance personnel and spend more on budget. In addition, they have more proactive maintenance policies, better planning and control systems, and more decentralised maintenance organisation structures in comparison to others.

\subsection{Maintenance perspective}

Maintenance perspective can be dealt with by analysing different dimensions. Tsang (2002) identified and discussed four strategic dimensions that are relevant to the maintenance function: (1) the choice between inhouse capability and outsourced service; (2) organisation of the maintenance function and the way maintenance tasks are structured; (3) the selection of maintenance policies; and (4) design of the infrastructure that supports maintenance. In this paper, more emphasis will be given to practices related to maintenance approaches and how they are selected.

\subsubsection{Maintenance approaches}

Several maintenance approaches, i.e. strategies and concepts, have been implemented by practitioners or suggested by intellectuals. Maintenance approaches and their development are discussed by many authors; see, for example (Moubray, 1991; Kelly, 1997; Mckone and Wiess, 1998; Dekker, 1996; Sherwin, 2000; Swanson, 2001; Tsang, 2002; Alsyouf, 2007). Usually, maintenance actions are aimed at minimising failure and the consequences of failure of industrial plant, machinery and equipment as far as possible. These actions can take several forms such as breakdown maintenance, preventive maintenance (PM), i.e. replacing components at a pre-specified time using statistical models based on collected historical failure data, or condition-based maintenance (CBM) by monitoring the condition of the component using one (or more) condition monitoring (CM) techniques. However, in all cases, the decision maker needs to select from all the applicable maintenance approaches the right policy for each component, module or equipment. The identification and implementation of the appropriate maintenance policy will enable the managers to avoid premature replacement costs, maintain stable production capabilities, and prevent the deterioration of the system and its components. (See among others Williams et al., 1994;
Mann et al., 1995; Dekker, 1996; Vineyard et al., 2000; Sherwin, 2000; Waeyenbergh and Pintelon, 2002.)

\subsubsection{Maintenance selection methods}

In the literature, it is possible to find methods that can help in selecting the right maintenance policy or action, such as methods that are based on modelling the time to failure and optimisation, e.g. age and block. (See among others, Barlow and Campo, 1975; Bergman, 1977; Murthy and Asgharizadeh, 1999; Sherwin, 2000; Campbell and Jardine, 2001; Marquez and Heguedas, 2002; Wang, 2002.) Furthermore, there are sets of rules such as the systematic approach of maintenance planning applied by reliability-centred maintenance (RCM) for selecting the suitable maintenance action (Moubray, 1991; Smith, 1993). Important elements in RCM methodology include identification of system functions and functional failures, as well as failure mode effects and criticality analysis (FMECA) and decision trees (Tsang, 2002). Additionally, there is the method of multiple criteria decision-making (MCDM), which is implemented in some cases such as Roubens (1996), Zanakis et al. (1998), Triantaphyllou and Lin (1996), Bevilacqua and Braglia (2000), Al-Najjar and Alsyouf (2003) and Wang et al. (2007).

\section{Method}

In the following we describe how the study was conducted. In particular we discuss the research method used in this study, i.e. participants, procedures and the data collection tool.

\subsection{Participants}

The empirical study was performed by conducting a cross-sectional survey to obtain information from the maintenance or production managers of Swedish firms (production plants) that have at least 100 employees. We obtained the addresses of 1440 Swedish firms from Statistics Sweden "Statistiska Centralbyrån" (SCB). The population was selected from the Swedish Standard Industrial Classification (SE-SIC) 2002. First, we surveyed every member of the selected population, i.e. 1440 firms. Out of the 1440 questionnaires that we sent by surface mail, 38 questionnaires were removed from the population for various reasons. However, the total number of respondents was 185 . This means that the response rate was only $13.2 \%$. Therefore, in order to improve the possibility of generalising the results we decided to restrict the studied population to the industries that had a high response rate. They were also characterised by having expensive down time due to high capital investment, which also meant that maintenance could have an important role. The size of the restricted population was thus 539 and the total number of respondents was 118 , hence, the overall response rate increased to about $22 \%$.

The respondents were distributed among the following industries: $55 \%$ of the respondents were in mechanical engineering, $16 \%$ wood and timber, $13 \%$ pharmaceutical 


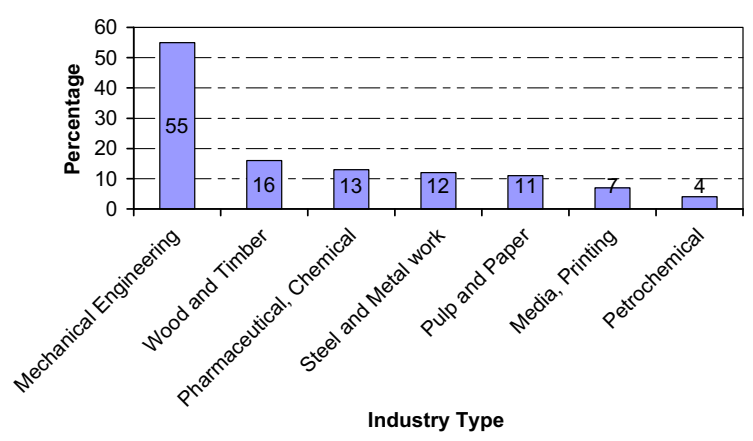

Fig. 2. Respondents' type of industry.

and chemical, $12 \%$ steel and metal work, $11 \%$ pulp and paper, $7 \%$ media and printing and 4\% chemical, see Fig. 2.

The surveyed respondents included 75 maintenance managers, 18 production managers, 9 technical managers and 16 other managers. The respondents were characterised by having long experience in their current position, for example, about $22 \%$ of the respondents had more than 10 years of experience in the current position.

The number of employees at these firms ranged from 37 to 2400 . The historical background of these firms was diverse. For example, the year that production began at these plants ranged from 1693 to 1996. However, only about $15 \%$ of them had started production before 1900 and about 50\% started after 1960. The equipment criticality in these plants was estimated on average as 54\% critical for production, $18 \%$ as critical for safety and environment, $18 \%$ as support equipment that reduced the production in the long run if was not maintained, $8 \%$ as non-essential (back-up) and $2 \%$ others.

\subsection{Data collection tool}

The questionnaire used in this study consisted of five main parts and 43 main questions. To guarantee that the questionnaire fulfilled the construct validity requirements, i.e. it was adequate and measured what it was supposed to measure, a special check list was used to test if the questionnaire covered all the aspects considered necessary, such as technical, financial, organisational, environmental and educational aspects.

One of the most important criteria of questionnaire design is that the questions should be short, relevant, and easy to understand. At the same time, it is very important to make sure that the respondents have interpreted the questions as intended. Therefore, the questionnaire was designed with structured questions in which the respondent could choose an answer from a set of listed possibilities. This is recommended for mail surveys, and when necessary, an open-ended option is used to guarantee that the respondent has interpreted the question as intended. This improves the validity and reliability of the instrument. To guarantee a high degree of content and construct validity, the questionnaire was based on the appropriate theory and literature and was pre-tested by academics and practitioners in the maintenance area to ensure that all the used terms were relevant and clear.
At the same time, all the procedures for data collection were written down in detail to ensure the repeatability of the process and enable good reliability.

\subsection{Procedure}

The designed questionnaire passed through all the procedures of drafting, pre-testing, finalising and production, first mailing, first reminder using mail, and second reminder using the telephone. Based on the study, objective questions were drafted to cover all relevant aspects. Both the question content and the wording were selected carefully. Then the questionnaire (written in English) went through a series of tests. The first test was performed by the designers, and then it was presented in a seminar as part of a yearly meeting with the centre of industrial competitiveness (CIC) at Växjö University. After that, other colleagues and Ph.D. students at the school tested a draft of the questionnaire translated into Swedish. All their comments were considered and incorporated in a revised version. The quality of translation was controlled and tested in a way that guaranteed interactive and back translation during every stage.

Then the Swedish version of the questionnaire was tested in the field by sending it with a covering letter to one of the companies participating in financing the research project, i.e. the Swedish terminal post in the town of Alvesta. The maintenance manager at the terminal post was asked to write his reflections on how clear the questions were and how easy they were to answer. After that, the questionnaire was revised and retested again with the same manager. When we were satisfied with the questionnaire it was reproduced and mailed. A mail survey was used to collect the empirical data. In a mail survey, the respondent can take more time to collect facts and talk with others. Another advantage of a written questionnaire is the avoidance of potential interviewer bias. However, the major weakness of a mail survey is the degree of non-response (Emory and Cooper, 1991).

\section{Results and discussion}

In the following we present the main results and findings obtained as a consequence of processing the collected data by descriptive statistics or factor analysis using SPSS software.

\subsection{Innovation and growth perspective}

The respondents were asked to rate how much emphasis was placed on a set of aspects using a 5-point scale. The scale used ranged from ( $1=$ Not emphasised $)$ to $(5=$ Very emphasised). In the following we present the results obtained for the three maintenance practices that belong to the innovation and growth perspective.

\subsubsection{Contributing to developing future machines}

The following three aspects that are related to the contribution of maintenance departments in designing 
and improving the production processes were analysed. It was found that "helping in designing the production processes" and "helping the purchasing department in selecting the right manufacturing equipment" were both emphasised with median ranks of 3 and 4, respectively. While "helping in improving the production processes" was emphasised with a median rank of 4 .

\subsubsection{Competence of maintenance human resources}

The average number of employees working in the maintenance department was 32. The number ranged from 0 to 750 employees, with a mode of 3 , first quartile of 5 , median of 10 , and third quartile of 28 employees. However, it was found that about two-thirds of the persons working in the maintenance department had more than 10 years working experience, see Fig. 3.

Only $4 \%$ of the people working with maintenance had experience of less than one year. On the other hand, on average, only $9 \%$ had a university education, $53 \%$ had a high school education and 38\% did not have a high school degree. However they had gained experience from working in industry and through industrial courses.

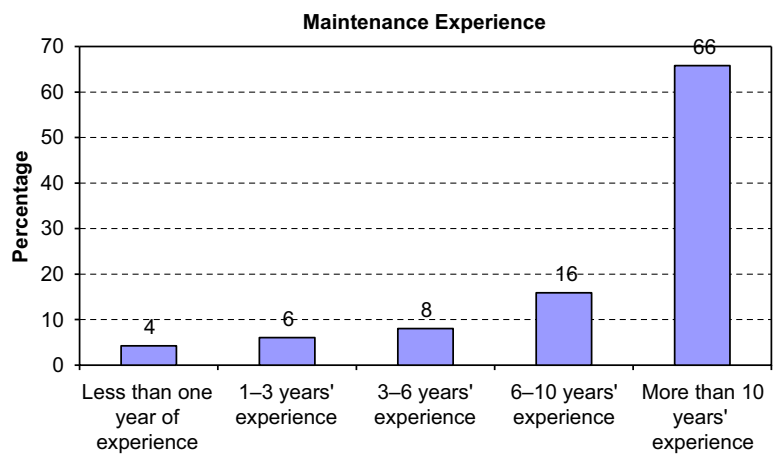

Fig. 3. Distribution of maintenance employees' experience.

\subsubsection{Investment in maintenance}

The turnover of the companies that owned the respondents' firms, in the year 2002, ranged from 1 to about 9000 million Swedish Krona (SEK) with a mean of 678 . The percentage of maintenance budget in comparison to the company turnover was on average about $4 \%$. A question was asked about the percentage of maintenance budget spent on education and training. The answers ranged from $0 \%$ to $20 \%$, with a mean value of about 4\%, see Fig. 4 .

However, about $17 \%$ of the respondents did not spend anything on education and training of personnel working in maintenance. This could be due to outsourcing, which consumed about $20 \%$ of the maintenance budget according to the respondents. Another question was asked about the portion of maintenance department time spent on education and training. It was found that on average it corresponded to about 4\%-an answer that matched the percentage of budget spent on education and training. This emphasises the reliability of the results obtained.

The contribution of maintenance to the performance and profitability of manufacturing systems is beyond question and has been emphasised by many studies, see among others Kutucuoglu et al. (2001), Mitchell et al. (2002) and Alsyouf (2007). However, it was found that about $70 \%$ of the respondents still believed maintenance is a necessary expense.

\subsection{Maintenance perspective}

In the following, we present the results concerning dimensions related to maintenance perspectives.

\subsubsection{Maintenance organisation and the way maintenance tasks are structured}

It was found that about $28 \%$ of the firms had no maintenance strategy or policy at all, about $48 \%$ had a

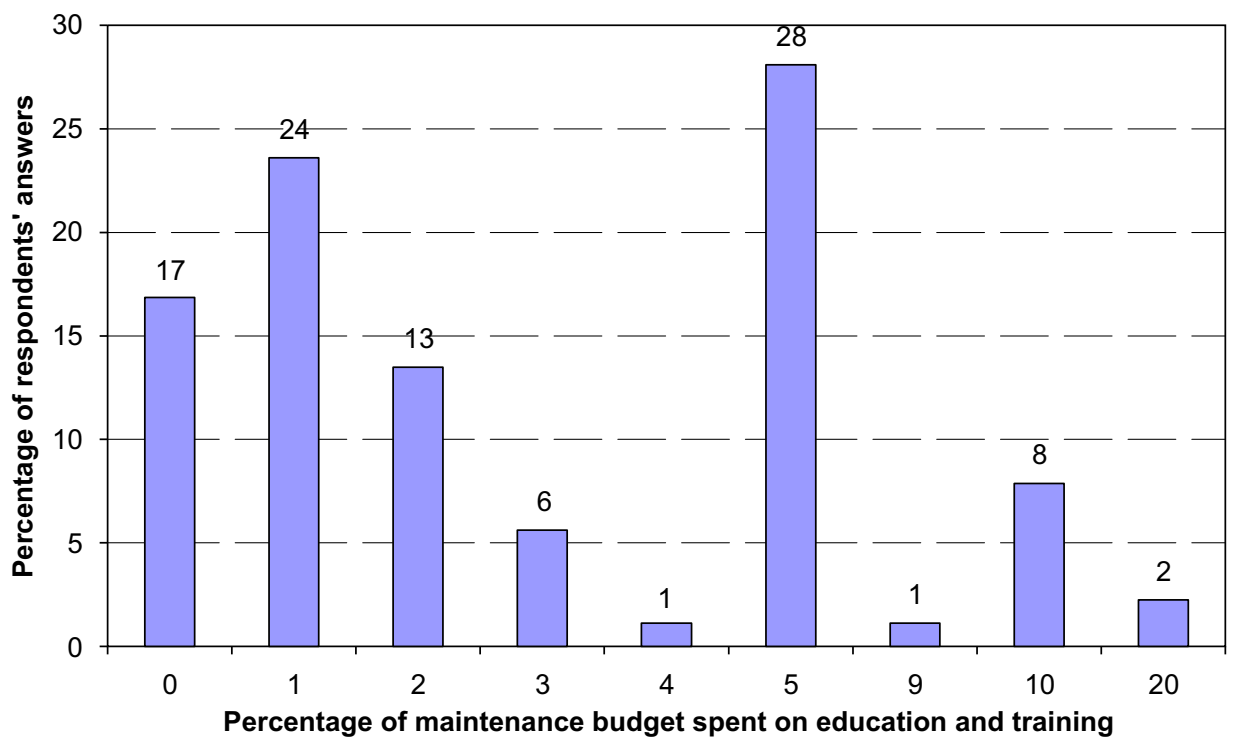

Fig. 4. Percent of maintenance budget spent on education and training. 


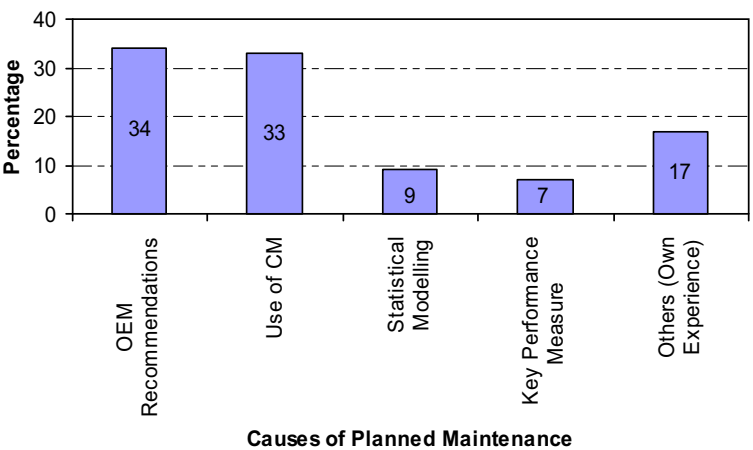

Fig. 5. Distribution of causes of planned maintenance.

written maintenance strategy or policy, and $24 \%$ had an oral one. Also, it was found that about $39 \%$ of the firms had a maintenance department that was organisationally independent of the production department, while in about $56 \%$, maintenance was organised as part of the production department. In about $5 \%$ of firms, maintenance and production had other organisational relations, for example maintenance being provided by an independent company within the mother company that sold service to the production plants. On the other hand, it was found that about $41 \%$ had a centralised organisation, $15 \%$ had a decentralised organisation, $41 \%$ had a combination of centralisation and decentralisation, and about 3\% had other types of organisation.

It was found that about $50 \%$ of the time was spent on planned tasks, about $37 \%$ was spent on unplanned tasks, and $13 \%$ was allocated for planning. However, the planned maintenance actions were based on the following originators $-34 \%$ the recommendation of the original equipment manufacturer (OEM), 33\% the use of condition monitoring techniques, $9 \%$ the use of statistical modelling of failure data, $7 \%$ the use of key performance measures, and $17 \%$ were based on other factors such as those related to the company's own experience, see Fig. 5.

\section{Maintenance approaches used in Swedish industry}

The respondents were asked to rate how much emphasis was placed on a set of maintenance approaches, i.e. failure based maintenance (FBM), preventive maintenance, operational or calendar-based maintenance, condition-based maintenance, reliability-centred maintenance, and total productive maintenance (TPM). We received 116 valid answers. The median value of the assessment of the level of importance placed on these approaches measured using a 5-point Likert scale is illustrated in Fig. 6.

As we can see, PM comes first, while CBM and FBM come in the second category, then comes TPM and finally comes RCM. However, since CBM involves many techniques, another question was asked about which $\mathrm{CM}$ techniques were emphasised, see Fig. 7.

Visual inspection is the most used CM technique, second comes the use of current torque and voltage as indicators of the machine's condition, then come a set of

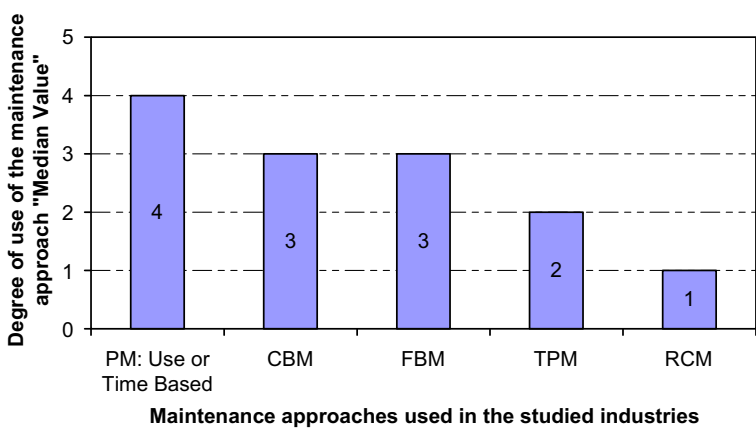

Fig. 6. Rank order of the maintenance approaches used in Swedish industries.

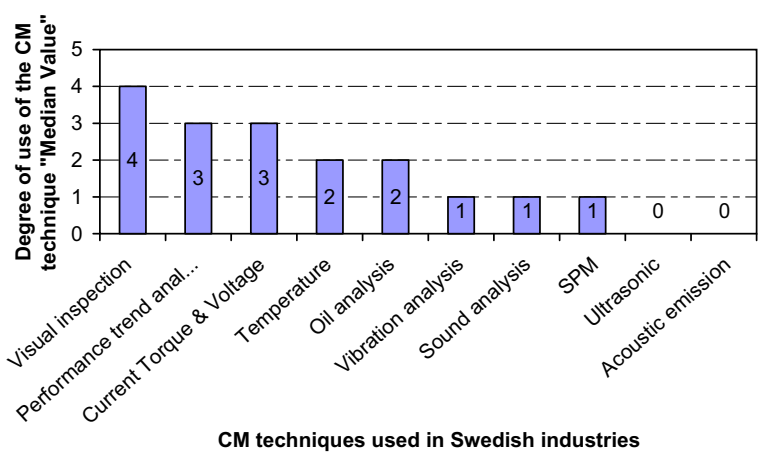

Fig. 7. Rank order of the CM techniques used in Swedish industries.

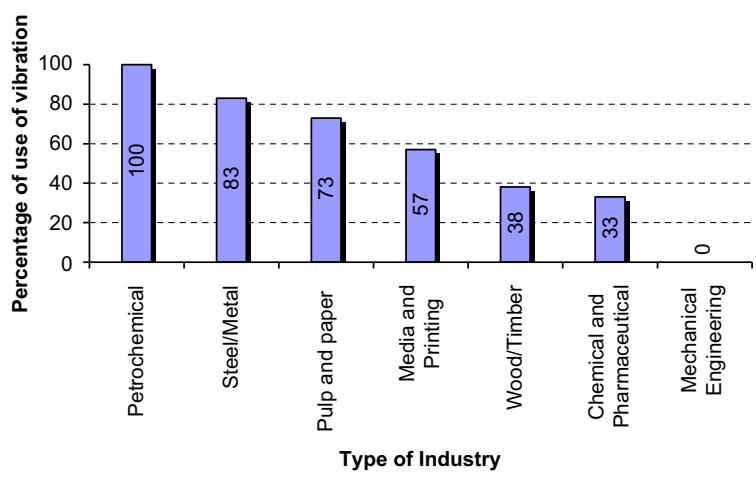

Fig. 8. Degree of use of vibration analysis in different types of industries.

techniques that include performance trend analysis, temperature monitoring and oil analysis. After that come vibration, sound analysis and SPM, and finally ultrasonic and acoustic emissions. However, these are general results; more detailed discussion of how these results could change with different types of industries is outside the scope of this paper. Nevertheless, as an example, we illustrate how the usage of vibration analysis varies with different types of industries, see Fig. 8.

In Fig. 8, we show the variation of the percentage of use of vibration analysis according to the type of industry. For example, all the respondents who belonged to the petrochemical industry indicated that they used vibration 
analysis. This means that vibration analysis is $100 \%$ used in the petrochemical, $83 \%$ used in the steel and metal work industries, 73\% used in the pulp and paper industry, about 57\% used in the media and printing industries, 38\% used in the wood and timber and 33\% used in chemical and pharmaceutical industries. On the other hand, it was found that vibration analysis is not used at all in mechanical engineering industries. This could be explained by the use of outsourcing.

\section{Identification of important factors used for maintenance selection}

The respondents were asked to rate how much emphasis was placed on a set of aspects when deciding or selecting a maintenance policy. We received 112 valid answers. To find the factors that the respondents considered important when they selected a maintenance policy, we used exploratory factor analysis. Factor analysis is a statistical approach that can be used to analyse interrelationships among a large number of variables and to explain these variables in terms of their common underlying dimensions (factors) (Hair et al., 1998). Therefore, using principal component factor analysis with varimax rotation, 13 variables, i.e. aspects considered when selecting a maintenance policy, were analysed, see Table 1 .

First we tried to ensure that the data were suitable for factor analysis. Therefore, we tested all the variables using both the Kaiser-Meyer-Olkin (KMO) measure of sampling adequacy (MSA) and Bartlett's test of sphericity. Thus, we obtained, as seen in Table 2, a KMO value of 0.886 and a Chi-Square value of 769 with significance of 0.000 . This indicated that the data could be used with factor analysis (Hair et al., 1998).

Knowing that the communalities are defined as the amount of variance accounted for by the factor solution for each variable, the researcher may, as a guideline, specify that at least one-half of the variance of each variable must be taken into account (Hair et al., 1998). In this case, the communality values (see Table 3 ) confirmed that the data were suitable for factor analysis, since they ranged from 0.438 to 0.891 , i.e. there were no values close

Table 2

KMO and Bartlett's test for selecting maintenance policy.

\begin{tabular}{ll}
\hline Kaiser-Meyer-Olkin measure of sampling adequacy & $\mathbf{0 . 8 8 6}$ \\
Bartlett's test of sphericity & \\
Approx. Chi-Square & $\mathbf{7 6 9 . 3 2 5}$ \\
df & $\mathbf{7 8}$ \\
Sig. & $\mathbf{0 . 0 0 0}$ \\
\hline
\end{tabular}

Table 3

Rotated component matrix, ${ }^{\mathrm{a}}$ communalities, eigenvalues and percentage of variance before and after rotation.

\begin{tabular}{|c|c|c|c|c|}
\hline & \multicolumn{4}{|c|}{ Component } \\
\hline & 1 & 2 & 3 & Communalities \\
\hline Cost effectiveness & 0.640 & 0.490 & -0.106 & 0.66 \\
\hline Product quality & 0.697 & 0.219 & 0.007 & 0539 \\
\hline Health and safety & 0.208 & 0.890 & 0.194 & 0.874 \\
\hline Environment & 0.224 & 0.858 & 0.323 & 0.891 \\
\hline Manufacturer recommendations & 0.003 & 0.213 & 0.788 & 0.668 \\
\hline Company policy & 0.377 & 0.152 & 0.575 & 0.496 \\
\hline Smooth production & 0.749 & 0.279 & 0.131 & 0.656 \\
\hline Lost production costs & 0.790 & 0.173 & 0.251 & 0.716 \\
\hline Replacement costs & 0649 & 0.222 & 0.170 & 0.499 \\
\hline On time delivery & 0694 & 0.109 & 0.490 & 0.733 \\
\hline Machine availability & 0.849 & 0.118 & 0.267 & 0.806 \\
\hline Investment cost & 0.554 & 0.272 & -0.239 & 0.438 \\
\hline Machine reliability & 0.786 & 0.002 & 0.232 & 0.672 \\
\hline \multicolumn{5}{|l|}{ Eigenvalues } \\
\hline Before rotation & 6.254 & 1.357 & 1.038 & \\
\hline After rotation & 4.865 & 2.143 & 1.641 & \\
\hline \multicolumn{5}{|l|}{$\%$ of variance } \\
\hline Before rotation & 48.104 & 10.442 & 7.986 & \\
\hline After rotation & 37.424 & 16.483 & 12.625 & \\
\hline
\end{tabular}

Note. Extraction method: principal component analysis. Rotation method: varimax with Kaiser normalisation.

a Rotation converged in 8 iterations.

Table 1

Aspects considered when selecting a maintenance policy.

Q How much emphasis is placed on each of the following factors when deciding or selecting a maintenance approach (strategy, policy, or technique):

\begin{tabular}{|c|c|c|c|c|c|c|}
\hline & NA & $\mathrm{NI}$ & & & & VI \\
\hline & 0 & 1 & 2 & 3 & 4 & 5 \\
\hline Cost competitiveness & $\square$ & $\square$ & $\square$ & $\square$ & $\square$ & $\square$ \\
\hline a. Product quality & $\square$ & $\square$ & $\square$ & $\square$ & $\square$ & $\square$ \\
\hline b. Health and safety requirements & $\square$ & $\square$ & $\square$ & $\square$ & $\square$ & $\square$ \\
\hline c. Environmental requirements & $\square$ & $\square$ & $\square$ & $\square$ & $\square$ & $\square$ \\
\hline d. Manufacturer recommendations & $\square$ & $\square$ & $\square$ & $\square$ & $\square$ & $\square$ \\
\hline e. Company policy & $\square$ & $\square$ & $\square$ & $\square$ & $\square$ & $\square$ \\
\hline f. Smooth production & $\square$ & $\square$ & $\square$ & $\square$ & $\square$ & $\square$ \\
\hline g. Breakdown cost (lost production) & $\square$ & $\square$ & $\square$ & $\square$ & $\square$ & $\square$ \\
\hline h. Replacement cost (man-hours and spare parts) & $\square$ & $\square$ & $\square$ & $\square$ & $\square$ & $\square$ \\
\hline i. On time delivery & $\square$ & $\square$ & $\square$ & $\square$ & $\square$ & $\square$ \\
\hline j. Availability & $\square$ & $\square$ & $\square$ & $\square$ & $\square$ & $\square$ \\
\hline k. Investment costs & $\square$ & $\square$ & $\square$ & $\square$ & $\square$ & $\square$ \\
\hline 1. Reliability & $\square$ & $\square$ & $\square$ & $\square$ & $\square$ & $\square$ \\
\hline
\end{tabular}

Note: NA (not applicable), NI (not important) and VI (very important). 


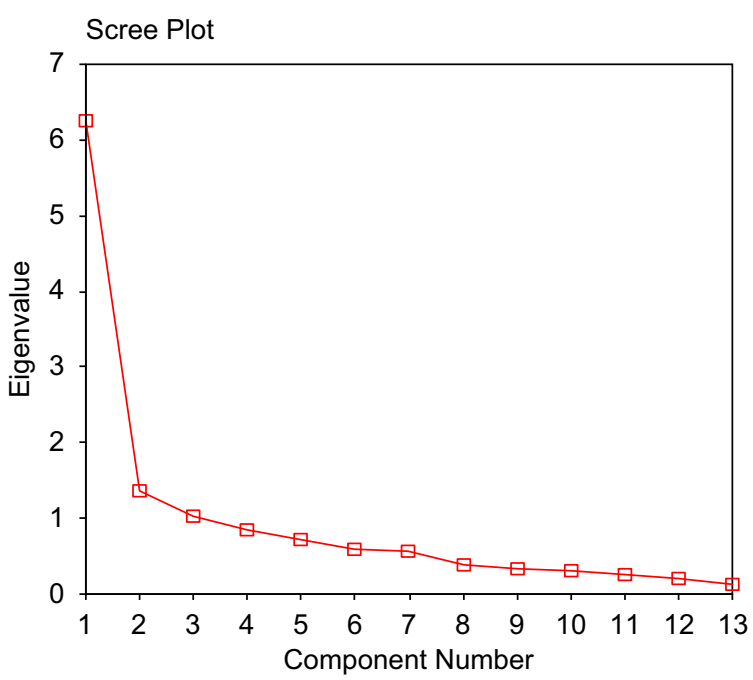

Fig. 9. Scree plot used for determining the number of factors extracted from variables related to maintenance selection.

to 0 or 1 . In addition, the measure of sampling adequacy was in the range 0.751 to 0.962 . Hair et al. (1998) illustrated that the MSA is calculated for both the entire correlation matrix and each individual variable. This evaluates the appropriateness of applying factor analysis; if the values are above one-half (i.e. 0.5) for either the entire matrix or an individual variable, this indicates appropriateness. In this case, all the values were greater than one-half, which meant that this set of data was suitable for use in factor analysis. Thus, we could derive new factors from the 13 variables. We determined the number of factors using an eigenvalue over one as an extraction criterion. Consequently, we obtained three factors that accounted for about $67 \%$ of the variation. See the results of factor analysis in Table 3 and Fig. 9.

Analysing the factor loading presented in Table 3, i.e. the correlation of each variable and the factor, can help in deriving the new constructs. The loading indicates the degree of correspondence between the variable and the factor. This is a means of interpreting the role that each variable plays in defining each factor. It ranges between -1 and +1 ; the higher loading absolute value makes the variable more representative of the factor. A loading was considered significant if it had an absolute value higher than 0.30. Since we have a factor solution in which all the variables have a significant loading on a factor, we identified the following three factors (constructs):

(1) The first factor (competitive advantages: businessoriented) includes the following variables that have a significant loading factor, ordered according to the value of their loading:

\begin{tabular}{ll}
\hline Variable & Loading \\
\hline Machine availability & 0.849 \\
Lost production costs & 0.790 \\
Machine reliability & 0.786 \\
Smooth production & 0.749 \\
Product quality & 0.697 \\
On time delivery & 0.694
\end{tabular}

$\begin{array}{ll}\text { Replacement costs } & 0.649 \\ \text { Cost effectiveness } & 0.640 \\ \text { Investment costs } & 0.554\end{array}$

(2) The second factor (safety and environment: the greens) includes the following variables:

\begin{tabular}{lc}
\hline Variable & Loading \\
\hline Health and safety & 0.890 \\
Environment & 0.858 \\
\hline
\end{tabular}

(3) The third factor (instructions: standards and procedures followed) includes:

\begin{tabular}{lc}
\hline Variable & Loading \\
\hline Manufacturer recommendations & 0.788 \\
Company policy & 0.575 \\
\hline
\end{tabular}

\section{Maintenance selection methods used in Swedish industry}

As a result of analysing about 115 valid answers obtained from the respondents when they were asked which maintenance selection methods were used when selecting a maintenance policy it was found that most of the firms, i.e. $81 \%$, did not use a specific method when selecting their maintenance policy. Instead, they used the knowledge and experience accumulated within the company, see Fig. 10.

In addition, about $31 \%$ of the respondents used a method based on modelling the time to failure and optimisation when selecting a maintenance policy. While about 10\% used FMECA and decision trees in their selection, only $2 \%$ used MCDM. On the other hand, about $6 \%$ mentioned using other maintenance selection methods such as monthly lists, documentation and experience, twice yearly major overhauls, maintenance costs, manufacturer recommendations, risk analysis and their own databases. It should be noticed that about $30 \%$ of the respondents used a combination of at least two methods

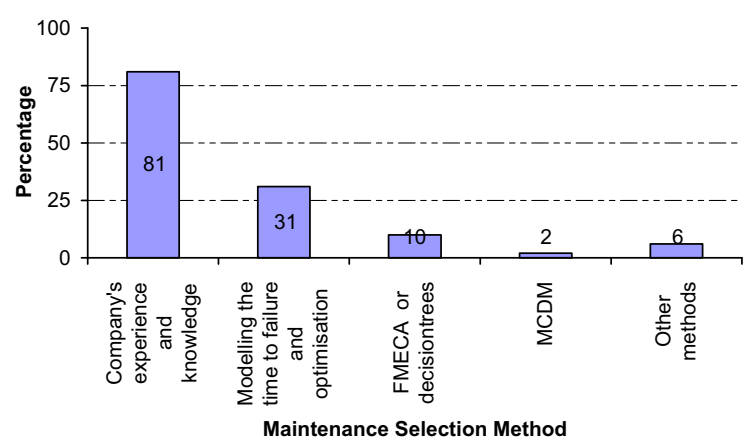

Fig. 10. Maintenance selection methods used in Swedish industry. 
at the same time, for example, experience and FMECA, or experience, modelling and optimisation.

\section{Identification of maintenance practices using factor analysis}

Here we tried to empirically find a construct that can describe the maintenance practices in Swedish industry using exploratory factor analysis. Therefore, using principal component factor analysis with varimax rotation we analysed 26 variables, i.e. maintenance activities, see Table 4

First we tried to ensure that the data were suitable for factor analysis. Therefore, we tested all the variables using both the Kaiser-Meyer-Olkin measure of sampling adequacy and Bartlett's test of sphericity. Thus we obtained, as shown in Table 5, a KMO value of 0.789 and a Chi-Square value of 1225 with significance 0.000 . This indicated that the data could be used with factor analysis.

The communality values, see Table 6 , also confirmed that the data were suitable for factor analysis since they ranged from 0.450 to 0.835 , i.e. there were no values close to 0 or 1 . Furthermore, all the variables had a communality value greater than or equal to one-half, e.g. only two variables had a value less than 0.50 .

In addition, the measure of sampling adequacy was in the range of $0.480-0.905$. This meant that it was suitable for use in factor analysis since all the MSA values were greater than one-half. Thus, we could derive new factors from the 26 variables. We determined the number of factors using an eigenvalue over one as an extraction

\section{Table 4}

Variables used in analysing maintenance practices.

Q How much emphasis is placed on each of the following activities where $1=$ not important and $5=$ very important. Restoring equipment to operation (acute)

Installing new equipment

Keeping the level low in spare parts inventory

Having inventory between machines, work in process/progress (WIP) Decreasing the repair time

Investing in improving the skills and competence of maintenance staff Use of computerized maintenance management systems (CMMS)

Analysing equipment failure causes and effects

Using historical failure data

Off-line monitoring of critical machinery purchasing (production is stopped during test)

On-line monitoring of critical machinery (test is done during production) Performing the maintenance tasks according to the original equipment manufacturer (OEM) recommendations

Performing the maintenance tasks based on condition monitoring

Performing the maintenance tasks based on statistical modelling of

failure data

Helping the purchasing department in OEM selection

Performing periodic planned replacement

Automatic diagnosis (expert system)

Remote diagnosis (measurements are sent to another places for analysis) Use of company-wide information for diagnosis

Cross functional groups (for instance, improvement groups)

Helping improve the production process

Helping design the production process

Recording the period and frequency of failures

Recording the period and frequency of short stoppages

Recording the poor quality rate

Annual overhaul
Table 5

KMO and Bartlett's test for maintenance activities.

\begin{tabular}{ll}
\hline Kaiser-Meyer-Olkin measure of sampling adequacy & $\mathbf{0 . 7 8 9}$ \\
Bartlett's test of sphericity & \\
Approx. Chi-Square & $\mathbf{1 2 2 5 . 1 7 3}$ \\
df & $\mathbf{3 2 5}$ \\
Sig. & $\mathbf{0 . 0 0 0}$
\end{tabular}

criterion. Consequently, we obtained seven factors that accounted for about $64 \%$ of the variation, see Table 6 .

Analysing the factor loading, i.e. the correlation of each variable and the factor, can help in deriving a new construct. In this case, a loading was considered significant if it had an absolute value higher than 0.30 . Since we had a factor solution in which all the variables had at least one significant loading on a factor, we identified the following seven factors (constructs):

(1) The first factor (the process-oriented "holistic" approach) included the following variables that had a significant loading factor, ordered according to the value of their loading:

\begin{tabular}{ll} 
Variable & Loading \\
\hline Helping in improving the production process & 0.79 \\
Helping the purchasing department in OEM selection & 0.74 \\
Using cross functional groups & 0.64 \\
Helping to design the production process & 0.62 \\
Using company-wide information for diagnosis & 0.56 \\
Performing periodic planned replacements & 0.42 \\
\hline
\end{tabular}

(2) The second factor (the autonomous approach) included the following variables:

Variable

Loading

Recording the periods and frequencies of failures

Recording the periods and frequencies of short stoppages

0.82

Recording poor quality rates

0.73

(3) The third factor (the predictive approach) included:

\begin{tabular}{lc}
\hline Variable & Loading \\
\hline Using CMMS & 0.67 \\
Investing in training and competence & 0.61 \\
Off-line monitoring & 0.58 \\
On-line monitoring & 0.52 \\
Performing maintenance tasks based on CM & 0.51 \\
Performing maintenance tasks based on statistical modelling & 0.51 \\
Analysing equipment failure causes and effects & 0.41 \\
\hline
\end{tabular}

(4) The fourth factor (the diagnostic "expert system" approach) included:

\begin{tabular}{lc} 
Variable & Loading \\
\hline Remote diagnostic & 0.82 \\
Automatic diagnostic & 0.75
\end{tabular}


Table 6

Rotated component matrix, ${ }^{\mathrm{a}}$ communalities, eigenvalues and percentage of variance before and after rotation.

\begin{tabular}{|c|c|c|c|c|c|c|c|c|}
\hline & \multicolumn{8}{|c|}{ Component } \\
\hline & 1 & 2 & 3 & 4 & 5 & 6 & 7 & Communalities \\
\hline Restoring equipment to operation (acute) & -0.01 & 0.00 & -0.12 & 0.00 & 0.00 & 0.64 & 0.15 & 0.45 \\
\hline Installing new equipment & 0.12 & -0.11 & 0.00 & -0.01 & 0.16 & 0.73 & 0.12 & 0.61 \\
\hline Keeping the level low in spare parts inventory & -0.01 & 0.01 & 0.00 & 0.30 & -0.01 & 0.01 & 0.74 & 0.65 \\
\hline Having inventory between machines (WIP) & -0.18 & 0.26 & 0.01 & 0.15 & 0.26 & 0.49 & -0.25 & 0.49 \\
\hline Decreasing the repair time & 0.01 & 0.11 & 0.16 & 0.00 & 0.34 & 0.23 & 0.68 & 0.68 \\
\hline Investing in improving the skills and competence of maintenance staff & 0.01 & 0.33 & 0.61 & -0.01 & 0.00 & 0.00 & 0.44 & 0.68 \\
\hline Use of (CMMS) & -0.01 & 0.12 & 0.67 & 0.01 & 0.00 & -0.13 & 0.26 & 0.55 \\
\hline Analysing causes and effects of equipment failure & 0.38 & 0.29 & 0.41 & -0.20 & 0.32 & 0.11 & 0.01 & 0.55 \\
\hline Using failure data & 0.26 & 0.32 & 0.28 & 0.00 & 0.62 & 0.00 & 0.18 & 0.66 \\
\hline Off-line monitoring & 0.19 & 0.00 & 0.58 & 0.41 & 0.00 & 0.00 & 0.00 & 0.54 \\
\hline On-line monitoring & 0.15 & 0.18 & 0.52 & 0.23 & 0.28 & 0.00 & -0.23 & 0.51 \\
\hline Following (OEM) recommendations & 0.11 & 0.00 & 0.00 & 0.16 & 0.80 & 0.24 & 0.00 & 0.73 \\
\hline Performing maintenance tasks based on $\mathrm{CM}$ & 0.39 & 0.00 & 0.51 & 0.21 & 0.23 & -0.01 & -0.12 & 0.53 \\
\hline Performing maintenance tasks based on statistical modelling of failure data & 0.10 & 0.37 & 0.51 & 0.16 & 0.16 & 0.36 & -0.17 & 0.61 \\
\hline Helping the purchasing department in OEM selection & 0.74 & -0.01 & 0.25 & 0.01 & 0.01 & 0.16 & -0.10 & 0.66 \\
\hline Performing periodic planned replacement & 0.42 & 0.13 & 0.29 & -0.01 & 0.36 & 0.01 & 0.21 & 0.46 \\
\hline Automatic diagnosis & 0.01 & 0.25 & 0.25 & 0.75 & 0.10 & 0.01 & 0.12 & 0.72 \\
\hline Remote diagnosis & 0.15 & 0.13 & 0.11 & 0.82 & 0.00 & 0.00 & 0.14 & 0.75 \\
\hline Use of company-wide information for diagnosis & 0.56 & 0.13 & 0.30 & 0.31 & 0.11 & 0.00 & 0.19 & 0.56 \\
\hline Cross functional groups (for instance, improvement groups) & 0.64 & 0.33 & 0.12 & 0.01 & 0.01 & -0.26 & 0.01 & 0.61 \\
\hline Helping improve the production process & 0.79 & 0.33 & -0.01 & 0.00 & 0.01 & 0.00 & 0.01 & 0.75 \\
\hline Helping design the production process & 0.62 & 0.46 & -0.01 & 0.25 & 0.17 & 0.11 & -0.14 & 0.73 \\
\hline Recording the period and frequency of failures & 0.16 & 0.84 & 0.22 & 0.01 & 0.18 & -0.43 & 0.16 & 0.84 \\
\hline Recording the period and frequency of short stoppages & 0.22 & 0.82 & 0.23 & 0.11 & 0.00 & 0.00 & 0.12 & 0.80 \\
\hline Recording the poor quality rate & 0.25 & 0.73 & 0.01 & 0.26 & 0.00 & 0.12 & 0.00 & 0.68 \\
\hline Annual overhaul & 0.35 & 0.26 & 0.22 & 0.20 & -0.37 & 0.48 & 0.12 & 0.66 \\
\hline \multicolumn{9}{|l|}{ Eigenvalues } \\
\hline Before rotation & 7.2 & 1.9 & 1.8 & 1.7 & 1.5 & 1.4 & 1.1 & \\
\hline After rotation & 3.3 & 3.1 & 2.7 & 2.0 & 1.9 & 1.8 & 1.7 & \\
\hline \multicolumn{9}{|l|}{$\%$ of variance } \\
\hline Before rotation & 27.7 & 7.2 & 7.1 & 6.3 & 5.7 & 5.3 & 4.1 & \\
\hline After rotation & 12.6 & 11.9 & 10.4 & 7.8 & 7.1 & 6.9 & 6.6 & \\
\hline
\end{tabular}

Note: Extraction method: principal component analysis. Rotation method: varimax with Kaiser normalisation.

a Rotation converged in 16 iterations.

(5) The fifth factor (the traditional preventive approach) included:

$$
\text { Variable }
$$

Performing maintenance tasks based on OEM recommendations 0.80 Using failure data

0.62

(6) The sixth factor (the reactive approach) included:

\begin{tabular}{ll}
\hline Variable & Loading \\
\hline Installing new equipment & 0.73 \\
Fire fighting (acute maintenance) & 0.64 \\
Having WIP between the machines & 0.49 \\
Performing annual overhauls & 0.48 \\
\hline
\end{tabular}

(7) The seventh factor (the strategic approach) included:

$$
\text { Variable }
$$
Loading
Based on the results of factor analysis, it was possible to identify seven main maintenance practices that are used by Swedish industry. The reactive approach focuses mainly on fire fighting, installing new equipment, using a WIP inventory between the machines to guarantee the functionality of the production lines, and performing annual overhauls. The preventive approach is characterised by performing maintenance tasks only based on the OEM and the usage of statistical methods to model the life function of the critical components based on failure data. The predictive approach is characterised by the usage of computerised maintenance and management systems (CMMS), investment in training and improving the personnel competence, using CM technology, and using methods suggested by RCM such as failure analysis, FMECA and statistical modelling. The diagnostic (expert systems) approach is characterised by the usage of remote and automatic diagnostic technology. The autonomous approach is based on TPM philosophy and depends mainly on measuring the overall equipment effectiveness. The lean approach focuses on reducing the losses resulting from, for example, having high levels of spare parts inventory and long repair times for machines. Finally, we have the proactive approach that is characterised by the 
following practices: helping to improve the production process; helping in the purchase of new equipment and selection of suppliers based on their previous experience; using cross functional groups to solve production problems; helping with designing and improving production processes; and using information available from the company to perform maintenance tasks and perform periodic planned replacement of critical components.

\section{Conclusions and comments}

The Swedish industry is aware of the role of maintenance in improving the reliability and maintainability of production systems during the early phases of design and during the development process of production systems. People are the most important resource in a maintenance department. They will manage, plan, supervise and execute all maintenance practices. The main way of developing the skills and competence of maintenance human resources in Swedish industry is using the accumulated knowledge and experience available in the company, and sending staff on related industrial courses. However, more investment should be allocated to education and training. In general, there is a need to spend and invest more in maintenance, which is still considered by the majority of Swedish industries as a necessary expense. The status and role of maintenance are not highly recognised in companies. For example, more than onehalf of the respondents of the survey indicated that they do not have any written maintenance strategy (this is similar to a result published by a previous study, see Jonsson, 1997). Moreover, the maintenance department still belongs from an organisational point of view to the production department. Top management and leadership should provide direction and support for the people working in maintenance. Furthermore, they should make greater efforts to link the maintenance strategy to the overall manufacturing and corporate strategy. There is a need to show the impact of maintenance on companies' performance.

Although about $13 \%$ of the maintenance department time is spent on planning maintenance tasks that are initiated mainly according to the original equipment manufacturer and the usage of condition monitoring techniques, nevertheless, about one third of the time is spent on unplanned tasks. This means that there is a need for greater adoption of maintenance concepts such as total productive maintenance and reliability-centred maintenance, which can result in selecting the right (cost effective) maintenance policy, i.e. preventive maintenance, condition-based maintenance, or failure-based maintenance. Furthermore, there is a need to emphasise more the use of advanced CM technologies such as oil, vibration, and sound analyses. These techniques have a great impact due to their role in identifying problems at an early stage and improving the effectiveness of maintenance task planning and scheduling. The lack (or ineffectiveness) of planning and scheduling can significantly restrict the maintenance department in achieving its objectives and can prevent the company from max- imising its business profit and from offering competitive advantages.

As a result of analysing the factors that are considered important when selecting a maintenance policy, it was possible to identify three main constructs: achieving competitive advantages (business-oriented), fulfilling safety and environmental requirements (the greens), and following the standards and procedures issued by the OEM or maintenance programs. In selecting a maintenance policy, Swedish maintenance departments depend mainly on the knowledge and experience accumulated within the company. It was possible to identify seven main maintenance practices in Swedish industry. These practices comply with what is known as recent advanced development of the maintenance concept. However, there is a need to investigate further the usage of these practices with various types of industry (this is outside the scope of this study). Finally, the results of the study highlight some of the maintenance practices in Swedish industries, with particular focus on the strengths and opportunities for improvement.

\section{Acknowledgements}

This study is a result of a research project that was financed by Växjö University through what was known as the Centre of Industrial Competitiveness (CIC). I would like to thank everyone that participated in this research project, in particular my colleague Anders Ingwald. In addition, I am grateful to all the respondents who answered the questionnaire. I also acknowledge the input from the Swedish terminal post in the town of Alvesta and thank those involved for their efforts and time spent in testing the questionnaire.

\section{References}

Al-Najjar, B., Alsyouf, I., 2003. Selecting the most efficient maintenance approach using fuzzy multiple criteria decision-making. International Journal of Production Economics 84, 85-100.

Al-Najjar, B., Alsyouf, I., 2004. Enhancing a company's profitability and competitiveness using integrated vibration-based maintenance: a case study. European Journal of Operational Research 157, 643-657.

Alsyouf, I., 2004. Cost Effective Maintenance for Competitive Advantages-Thesis for the Degree of Doctor of Philosophy (Terotechnology). School of Industrial Engineering. Växjö University Press, Acta Wexionensia, Sweden.

Alsyouf, I., 2006. Measuring maintenance performance using a balanced scorecard approach. Journal of Quality in Maintenance Engineering 12 (2), 133-149.

Alsyouf, I., 2007. The role of maintenance in improving company productivity and profitability. International Journal of Production Economics 105, 70-78.

Barlow, R.E., Campo, R.A., 1975. Total time on test processes and applications to failure data analysis. In: Barlow, R.E., Fussell, J. Singpurwalla, N.D. (Eds.), Reliability and Fault Tree Analysis. SIAM, Pennsylvania.

Bergman, B., 1977. Some graphical methods for maintenance planning. In: Proceeding of IEEE, Reliability and Maintainability Symposium, Philadelphia, 18-20 January, p. 467.

Bevilacqua, M., Braglia, M., 2000. The analytical hierarchy process applied to maintenance strategy selection. Reliability Engineering and System Safety 70, 71-83.

Blanchard, B.S., 2004. Logistics Engineering and Management, sixth ed Prentice-Hall, Pearson.

Bob, V., 2007. Experts lay out a case for ROI of maintenance. Plant Engineering 61 (8), 12 
British Standard Glossary of Terms Used in Terotechnology, 1993. BS 3811.

Campbell, J.D., Jardine, A.K.S., 2001. Maintenance Excellence: Optimising Equipment Life Cycle Decisions. Marcel Dekker, New York.

Cholasuke, C., Bhardwa, R., Antony, J., 2004. The status of maintenance management in UK manufacturing organisations: results from a pilot survey. Journal of Quality in Maintenance Engineering 10 (1), 5-15.

Dekker, R., 1996. Applications of maintenance optimisation models: a review and analysis. Reliability Engineering and System Safety 51, 229-240.

Dowlatshahi, S., 2008. The role of industrial maintenance in the maquiladora industry: an empirical analysis. International Journal of Production Economics 114 (1), 298-307.

Emory, W., Cooper, D., 1991. Business Research Methods, fourth ed. Irwin, Homewood, IL.

Hair, J., Anderson, R., Tatham, R., Black, W., 1998. Multivariate Data Analysis, fifth ed. Prentice-Hall International, Inc., USA.

Holmberg, K., 2001. Competitive reliability 1996-2000. Technology Programme Report 5/2001, Final Report, National Technology Agency, Helsinki.

Jonsson, P., 1997. The status of maintenance management in Swedish manufacturing firms. Journal of Quality in Maintenance Engineering 3 (4), 233-258.

Jonsson, P., 2000. An empirical taxonomy of advanced manufacturing technology. International Journal of Operations and Production Management 20 (12), 1446-1474.

Kamoun, F., 2005. Toward best maintenance practices in communications network management. International Journal of Network Management 15 (5), 321-334.

Kelly, A., 1997. Maintenance Strategy. Butterworth Heinemann, Oxford, UK.

Kelly, A., 2006. Managing Maintenance Resources. Butterworth-Heinemann, Oxford, UK

Kumar, S., Chattopadhyay, G., Kumar, U., 2007. Reliability improvement through alternative designs-a case study. Reliability Engineering and System Safety 92 (7), 983-991.

Kutucuoglu, K., Hamali, J., Irani, Z., Sharp, J., 2001. A framework for managing maintenance using performance measurement systems. International Journal of Operations and Production Management 21 (1/2), 173-194

Luce, S., 1999. Choice criteria in conditional preventive maintenance: short paper. Mechanical Systems and Signal Processing 13 (1), 163-168.

Luxhoj, J., Riis, J., Thorsteinsson, U., 1997. Trends and perspectives in industrial maintenance management. Journal of Manufacturing Systems 16 (6), 437-453.

Mann, L., Saxena, A., Knapp, G.M., 1995. Statistical-based or conditionbased preventive maintenance? Journal of Quality in Maintenance Engineering 1 (1), 46-59.

Marquez, A.C., Heguedas, A.S., 2002. Models for maintenance optimisation: a study of repairable systems and finite time periods. Reliability Engineering and System Safety 75, 367-377.

Mckone, K., Wiess, E., 1998. TPM: planned and autonomous maintenance: bridging the gap between practice and research. Production and Operations Management 7 (4), 335-351.
Meulen, P., Petraitis, M., Pannese P., 2008. Design for maintenance. In: IEEE/SEMI Advanced Semiconductor Manufacturing Conference, pp. 278-281.

Mitchell, E., Robson, A., Prabhu, V., 2002. The impact of maintenance practices on operational and business performance. Managerial Auditing Journal 17 (5), 234-240.

Moubray, J., 1991. Reliability Centred Maintenance. Butterworth Heinemann, Oxford, UK.

Murthy, D.N.P., Asgharizadeh, E., 1999. Optimal decision making in a maintenance service operation. European Journal of Operational Research 116, 259-273.

Nakajima, S., 1988. Introduction to Total Productive Maintenance, TPM. Productivity Press, Cambridge.

Pinjala, S.K., Pintelon, L., Vereecke, A., 2006. An empirical investigation on the relationship between business and maintenance strategies. International Journal of Production Economics 104 (1), 214-229.

Roubens, M., 1996. Choice procedures in fuzzy multi-criteria decision analysis based on pair-wise comparisons. Fuzzy Sets and Systems 84, $135-142$.

Sherwin, D.J., 2000. A review of overall models for maintenance management. Journal of Quality in Maintenance Engineering 6 (3), 138-164.

Smith, A.M., 1993. Reliability-Centered Maintenance. McGraw-Hill, New York.

Stephen, T.D., 2000. Positioning maintenance as a competitive advantage. Plant Engineering 54 (5), 66-69.

Swanson, L., 2001. Linking maintenance strategies to performance. International Journal of Production Economics 70 (3), 237-244.

Swanson, L., 2003. An information-processing model of maintenance management. International Journal of Production Economics 83 (1), 45-64.

Triantaphyllou, E., Lin, C., 1996. Development and evaluation of five multi-attribute DM methods. International Journal of Approximate Reasoning 14 (4), 281-310.

Tsang, A.H.C., 2002. Strategic dimensions of maintenance management. Journal of Quality in Maintenance Engineering 8 (1), 7-39.

Vineyard, M., Amoako-Gyampah, K., Meredith, J., 2000. An evaluation of maintenance policies for flexible manufacturing systems: a case study. International Journal of Operations and Production Management 20 (4), 409-426.

Waeyenbergh, G., Pintelon, L., 2002. A framework for maintenance concept development. International Journal of Production Economics 77 (3), 299-313.

Wang, H., 2002. A survey of maintenance policies of deteriorating systems. European Journal of Operational Research 139, 469-489.

Wang, L., Chu, J., Wu, J., 2007. Selection of optimum maintenance strategies based on a fuzzy analytic hierarchy process. International Journal of Production Economics 107 (1), 151-163.

Williams, J., Davies, A., Drake, P., 1994. Condition-Based Maintenance and Machine Diagnostics. Chapman \& Hall, London.

Zanakis, S., Solomon, A., Wishart, N., Dublish, S., 1998. Multi-attribute decision-making: a simulation comparison of select methods. European Journal of Operation Research 107, 507-529.

Zhu, G., Gelders, L., Pintelon, L., 2002. Object/objective-oriented maintenance management. Journal of Quality in Maintenance Engineering 8 (4), 306-318. 